\title{
Research Paper: Assessing an Eliciting Narrative Tool Used for Studying the Development of Persian-speaking Children's Narrative Discourse Skills
}

\author{
Setareh Mojahedi Rezaeian ${ }^{*}$ (D), Abbas Ali Ahangar ${ }^{1}$ (D), Peyman Hashemian² (D, Mehrdad Mazaheri ${ }^{3}$ (D)
}

1. Department of English Language and Literature, Faculty of Literature and Humanities, University of Sistan and Baluchestan, Zahedan, Iran

2. Medical Genetics Research Center, Mashhad University of Medical Sciences, Mashhad, Iran.

3. Department of Psychology, Faculty of Education and Psychology, University of Sistan and Baluchestan, Zahedan, Iran.

\begin{tabular}{|c|c|}
\hline $\begin{array}{l}\text { Use your device to scan } \\
\text { and read the article online }\end{array}$ & $\begin{array}{l}\text { Citation: Mojahedi Rezaeian S, Ahangar A, Hashemian P, Mazaheri M. Assessing an Eliciting Narrative Tool Used for } \\
\text { Studying the Development of Persian-speaking Children's Narrative Discourse Skills. Journal of Modern Rehabilitation. 2020; } \\
\text { 14(1):55-68. http://dx.doi.org/10.32598/JMR.14.1.7 }\end{array}$ \\
\hline & dol'http://dx.doi.org/10.32598/JMR.14.1.7 \\
\hline
\end{tabular}

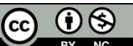

Article info:

Received: 05 May 2019

Accepted: 11 Oct 2019

Available Online: 01 Jan 2020

\section{Keywords:}

Narrative, Assessment, Age, Gender, Persian-speaking children

\section{ABSTRACT}

Introduction: Developing children's skills in producing oral narratives can reflect their linguistic and cognitive abilities. However, to evaluate these abilities appropriately, it is necessary to find and apply an efficient narrative assessment tool. This study primarily aimed to assess the reliability and validity of a picture story, as a narrative eliciting tool, based on Persianspeaking children's narratives. This assessment is going to be done at the microstructure and macrostructure levels. Furthermore, to evaluate the power of the assessment tool, we explored the effect of age and gender variables on using different narrative elements at the microstructure and macrostructure levels.

Materials and Methods: We used a picture story, "Frog, where are you?" to elicit ora narratives in 48 subjects, including 7-, 9-, and 11-year-old boys and girls. The reliability and validity of the tool were respectively assessed by test-retest and factor analysis.

Results: The findings indicated a significantly high correlation between the evaluated features based on test-retest. Besides, factor analysis revealed four categories: sentence structures, references, conjunctions, measures of story length. They were valid indicators for assessing Persian-speaking children's narratives. The results also showed a statistically significant difference among different age groups, but an insignificant effect of gender on using discursive features in the tales.

Conclusion: The picture story "Frog, where are you?" can be used as a reliable and valid narrative eliciting tool for Persian data at the microstructure and macrostructure levels. Also, the age factor, but not the gender one, affects the stories recited by Persian children.

* Corresponding Author:

Setareh Mojahedi Rezaeian, PhD.

Address: Department of English Language and Literature, Faculty of Literature and Humanities, University of Sistan and Baluchestan, Zahedan, Iran. Tel: +98 (915) 3044094

E-mail: setareh.mojahedi@pgs.usb.ac.ir 


\section{Introduction}

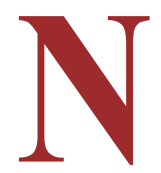

arrative is a spoken or written description of connected discourse events generally in the temporal order of happening [1-3]. It reflects a uniquely human capability to recollect experiences, so it is known as one of the most central and universal types of discourse [4]. Therefore, identifying and evaluating narrative production and comprehension characteristics can open windows into linguistic and cognitive abilities, which are closely interrelated with educational and academic developments.

Since the narrative is deemed to be a multifaceted task, it has extensively been investigated in different languages within various groups, including typically-developed children and children with language impairment, from different perspectives [5-13]. Accordingly, the storytelling method, for example, based on a picture story, is one of the efficient tools of collecting linguistic data and then assessing narrative abilities [12]. Hence, specialists, who reflect on language development in their research, are increasingly interested in determining and applying practical approaches, efficient eliciting tools, and the most associated contextual features.

These efforts are essential in analyzing children's narrative skills regarding different factors such as age, gender, bilingualism, etc. Currently, it is believed that no comprehensive "gold standard guidelines" [14] exist to evaluate narrative features, particularly for Persian narrative assessment. However, to understand children's narrative characteristics, we should assess the specific features of a narrative based on both the microstructure (local structure) and macrostructure (global structure) levels [14-19].

Narrative microstructure generally assesses intrinsic properties $[14,16]$ and the local coherence relationships [20], such as sentence structure. Nevertheless, regarding language-specific characteristics, it is crucial to determine which linguistic features should be investigated in a narrative at the microstructure level. On the other hand, narrative macrostructure features are influenced by the narrator's language abilities, for example, to narrate story events based on a hierarchical mental representation and also different cognitive processes such as memory or causal thinking [10, $16,21,22]$. Therefore, the macrostructure can be considered as the global coherence relationships in narratives [20], which represents story grammar [23, 24].

Story grammar is regarded as a schema in semantic memory that identifies the typical or expected arrangement of events in a story. In general, story grammars view narra- tives as consisting of a setting, one or more episodes, and an ending [20]. However, as to the notion of story grammar, some researchers tend to investigate narratives at the macrostructure level based on six main components of setting, initiating event, internal response, explicit goal, attempts, and outcomes $[10,25,26]$.

In contrast, other researchers abridge these components into three crucial ones: initial event, attempts, and resolution [27, 28]. In another approach, some researchers apply Goal-Attempt-Outcome (GAO) schema to investigate children's narratives [29, 30]. On the whole, most narratives are typically formed based on initiating event, attempt(s), result(s), and probable subsections. So the analyzer should adopt one of these approaches according to his/her research aims. In line with these issues, different studies investigating children's narrative skills indicate developmental steps of the macrostructure in their productions. They specify that the comprehension of the story schema occurs early in children, about three years old, while the production of the story schema is a developmental and gradual process [15, 27, 31].

Additionally, in investigating the narrative discourse, methods of language sampling (i.e., data gathering, transcribing, parsing, and analyzing) typically depend on the adopted approach and language specifics. For example, since Persian is a pro-drop language, the inflection of the verb reflects the subject in the case of complete ellipsis (the zero subjects) [32]. So, this characteristic extensively influences the selection of various linguistic devices to encode, specifically reference in a narrative. According to the considerable works on the narrative analysis, the unit of analysis in narrative discourse is T-unit, which is one independent clause and any number of dependent clauses [7, 14, 16, 33].

Importantly, the reliability and validity of any assessment tool should be explored to confirm whether reliable and valid data are gathered. One way of evaluating reliability is by test-retest method, which assesses the stability of a measure over time [34]. The validity of the test can also be investigated by confirmatory factor analysis (CFA) to examine interrelationships among a group of items [35]. Correspondingly, the study of narrative levels and categories provides valuable concurrent and predictive validity not only for the current language comprehension and production characteristics and abilities but also their future language skills and behavior $[36,37]$.

Concerning age, the development of narrative abilities begins early in childhood, and its development is significantly correlated with age $[38,39]$. Hence, along with the development of linguistic and cognitive knowledge, chil- 
dren's narrative skills development will carry on through early adulthood $[39,40]$. Nevertheless, there are contradictory reports about gender effect on the children's language developmental skills. Some studies reported that girls were generally more advanced in verbal skills than boys [41-43]. Conversely, some studies revealed similar verbal abilities or negligible differences between genders $[44,45]$.

To the best of our knowledge, very few researchers have addressed the reliability and validity of narrative eliciting tools in Persian. In their study, Soleymani, Nematzadeh, Gholami Tehrani, Rahgozar, and Schneider [46] determined how to elicit language samples in 5- to 6-year-old Persian-speaking children's narratives by developing two sets of picture stories of different lengths. They investigated on which language measures should be analyzed, and also whether these analyses are reliable. They demonstrated that language ability could be more reliably assessed when longer language samples were collected. They also claimed that "Frog, where are you?" picture storybook [47] did not reliably motivate the Persian-speaking children to narrate. However, the average number of sentences produced by three children using the Edmonton narrative norms instrument as developed in Schneider, Dubé, and Hayward [48] was much higher than for "Frog, where are you?" [47].

In a descriptive study, Qasemi, Nakhshab, Alineghad, Shafiei, and Tazhibi [49] examined language structures in spontaneous narrations produced by 126 Persian-speaking 4-year-old children, based on a picture book, regarding the gender factor implementing Narrative Assessment Protocol (NAP). They found no significant difference between 4-year-old girls and boys in using sentence structure, phrase structure, modifiers, nouns, and verbs.

This study aimed to determine which discursive features at the microstructure and macrostructure levels to describe and analyze the narrative of the Iranian elementary school children. Specifically, this study was conducted to assess the reliability and validity of "Frog, where are you?" [47] picture story for eliciting children's narrative skills based on Persian data. To achieve these goals, we explored narratives in terms of two parameters: microstructure and macrostructure levels.

The former included four general aspects of narrative discourse: 1. Sentence structure; comprising compound, complex, negative, interrogative sentences; 2 . Reference, containing full noun phrases, independent pronouns, dependent pronouns, complete ellipsis, and inflection of the verb; 3. Conjunctions, including associative, additive, adversative conjunctions, and developmental marker; and 4. Measures of story length, consisting of the number of total words (e.g., noun, verb, adjective, adverb, and preposition) number of total sentences, and semantic information.

Besides, at the level of macrostructure, causal relationships of the story were investigated in terms of initiating event, attempts, and resolution. In particular, this study investigated developmental patterns according to age and gender factors. These patterns would reflect on the discursive features in Persian-speaking school children and show the assessment power of this eliciting narrative tool. Consequently, the present study suggests the following research questions:

1. Can the picture storybook, "Frog, where are you?" [47], be applied as a reliable eliciting narrative tool for Persianspeaking children's narratives?

2. Can the picture storybook, "Frog, where are you?" [47], be applied as a valid eliciting narrative tool for Persian-speaking children's narratives?

3. Is there any significant difference in using different narrative features at the microstructure and macrostructure levels in Persian-speaking children's narrative discourse regarding their age?

4. Is there any significant difference in using different narrative features at the microstructure and macrostructure levels in Persian-speaking children's narrative discourse regarding their gender?

\section{Materials and Methods}

\section{Study participants}

The children who participated in this study were in the three age groups of 7, 9, 11 years old boys and girls, each group consisting of 8 subjects $(\mathrm{N}=48)$. They were all monolingual Persian-speaking students in primary schools of Mashhad, a city in Iran. The inclusion criterion was the production of at least 50 or more utterances, based on picture wordless book of "Frog, where are you?" [47] by each subject to determine the Mean Length of Utterance (MLU) (Table 1). Generally, 50 to 100 utterances are regarded as a sufficient narrative sample for analyzing a speaker's overall production. An utterance can be a sentence or a shorter unit.

To determine the speaker's MLU, after counting morphemes for each utterance, they are totaled and then divided by the number of utterances. Usually, higher MLU, up to 4.0 , corresponds to a rise in utterance complexity [50]. Furthermore, according to their available school profile, special educational needs and clinical diagnosis were not reported 
for these groups of the students. The subjects' parents and their teachers signed the consent form. Out of 56 subjects tested, eight children were excluded from the research, one child made a very fantasy and unbelievable story, two children were unwilling to tell the whole story, and four children were absent in the spring test.

\section{Data collection procedure}

For conducting the eliciting narrative test, formal permission was first taken from Mashhad Education and Training Administration. All children were individually tested in a quiet room in their school. They were asked to participate in a "story-telling game," in which they had to tell a story for one of the researchers who could not simultaneously see the picture storybook. The first test was directed in the fall, 2016, and the retest in the spring, 2017. A 24-page picture wordless book, "Frog, where are you?" [47] was used to elicit oral narratives. The story is about a boy who has a dog and a frog. After the frog escapes, the boy and his dog search for different places to find the frog.

During the search, they encounter different animals and events. The outcome of this search is finding the frog with a family in the forest. This story was chosen as a narrative elicitation tool because, according to some researchers and linguists, it has widely been used to investigate narratives in many different languages, by typically-developing children $[27,51]$ or children with some language impairments [10, $13,52,53]$. Moreover, the complexity of the causal relationships between events, appearance, and disappearance of the story characters and different settings make the subjects to recall their both linguistic and cognitive knowledge. Therefore, as a narrative tool, it can be not only a diagnostic tool but also a research tool for comparing Persian language narrative characteristics, particularly children's narratives, with those of other languages. Furthermore, analyzing narrative skills by using picture stories can be a valuable tool because the same scene is narrated by speakers $[27,54]$.

First, one of the researchers told the task of telling a narrative to each child individually. The children were allowed to turn the pages of the book. Then, it was explained that this is a picture book, and the child should narrate a story based on the pictures. During data eliciting, the researcher intervened as little as possible and merely used some phatic expressions or sentences such as "uhhuh" and "Well, that's right," or asked general questions, e.g., "Then, what happened?" or repeated the last produced sentence to motivate the child to continue. A voice recorder recorded the produced narratives. Generally, producing a narrative took about 10-15 min.

\section{Data analysis}

Then, all the narratives were transcribed word by word. In the next phase, unnecessary utterances such as questions asked by the children to get information (e.g., "Is this an owl?") were eliminated from the analysis. The unit of analysis was T-unit. At microstructure level, the correlation between applying sentence structure (following Justice et al [16]), reference, conjunctions (following Levinsohn [2]), and measures of story length (following Norbury and Bishop [10] [Appendix A]) were calculated in the fall and spring tests (for descriptions and Persian examples of the categories [Appendix B]). The microstructure level of the narrative and narrative analysis literature, as well as language-specific features of Persian, were chosen to study the developmental representation of complexity levels of the sentence.

This information provides sufficient information to refer to any character without ambiguity, employ conjunctions to indicate causal relationships between different narrative elements, and apply various types of words. Furthermore, the macrostructure level was explored regarding initiating events, attempts, and resolution, as developed by Berman and Slobin [27]. In this respect, for initiating an event, two points were specified if escaping the frog and searching the bedroom by the boy were stated, and one point for mentioning one of these propositions. As for attempts, the children received one point for stating one search event and two points for talking about two or more search events. Similarly, as to resolution, two points were allocated for mentioning finding the frog and taking it home, and one point for one of the propositions. Hence, a maximum of six points could be received by the children at the macrostructure level.

Then, from 48 narratives, ten transcribed narratives were analyzed by an expert in linguistics to determine the interrater reliability of the data analysis. The point-by-point agreement, which was $89 \%$ or higher for all categories at the levels of microstructure and macrostructure, was used to calculate inter-rater reliability of variables. The reliability and validity of the collected data from fall and spring test were assessed through correlation and factor analysis in SPSS. Furthermore, the effect of age and gender were evaluated on applying the given discursive features in the narratives.

\section{Results}

\section{Reliability of the narrative eliciting tool}

Regarding the first study question, to evaluate the reliability of the narrative eliciting tool, we used the test-retest method with an interval of six months (fall to spring). The Pearson correlation coefficients of the features of sentence 
Table 1. Demographic characteristics of the subjects

\begin{tabular}{lcccc}
\hline \multicolumn{1}{c}{ Variables } & Minimum & Maximum & Mean \pm SD \\
\hline Male $(\mathrm{n}=24)$ & Age $(\mathrm{y})$ & 6.83 & 11.50 & $9.17 \pm 1.69$ \\
& MLU & 3.20 & 6.46 & $4.43 \pm 0.69$ \\
Female $(\mathrm{n}=24)$ & Age $(\mathrm{y})$ & 6.83 & 11.41 & $9.16 \pm 1.66$ \\
& MLU & 3.94 & 5.65 & $4.71 \pm 0.42$ \\
\hline
\end{tabular}

MLU: Mean Length of Utterance.

Table 2. The correlations of the microstructure and macrostructure features

\begin{tabular}{|c|c|c|c|}
\hline Variables & \multirow{2}{*}{ Categories } & \multirow{2}{*}{ Correlation } & \multirow{2}{*}{$\mathbf{P}$} \\
\hline A. Microstructure & & & \\
\hline \multirow{4}{*}{ I. Sentence structure } & 1. Compound sentence & 0.885 & 0.001 \\
\hline & 2. Complex sentence & 0.838 & 0.001 \\
\hline & 3. Negative sentence & 0.457 & 0.001 \\
\hline & 4. Interrogative sentence & 0.613 & 0.001 \\
\hline \multirow{5}{*}{ II. Reference } & 1. Full noun phrases & 0.727 & 0.001 \\
\hline & 2. Independent pronouns & 0.681 & 0.001 \\
\hline & 3. Dependent pronouns & 0.786 & 0.001 \\
\hline & 4. Complete ellipsis & 0.783 & 0.001 \\
\hline & 5. Inflection of the verb & 0.745 & 0.001 \\
\hline \multirow{4}{*}{ III. Conjunctions } & 1. Associative conjunctions & 0.839 & 0.001 \\
\hline & 2. Additive conjunctions & 0.791 & 0.001 \\
\hline & 3. Adversative conjunctions & 0.597 & 0.001 \\
\hline & 4. Developmental markers & 0.839 & 0.001 \\
\hline \multirow{8}{*}{ IV. Measures of story length } & 1. Number of total words & 0.738 & 0.001 \\
\hline & a. Noun & 0.787 & 0.001 \\
\hline & b. Verb & 0.803 & 0.001 \\
\hline & c. Adjective & 0.856 & 0.001 \\
\hline & d. Adverb & 0.575 & 0.001 \\
\hline & e. Preposition & 0.796 & 0.001 \\
\hline & 2. Number of total sentences & 0.923 & 0.001 \\
\hline & 3. Semantic information & 0.923 & 0.001 \\
\hline \multirow{3}{*}{ B. Macrostructure } & 1. Initiating event & 0.788 & 0.001 \\
\hline & 2. Attempts & - & - \\
\hline & 3. Resolution & 0.434 & 0.002 \\
\hline
\end{tabular}


Table 3. Construct validity of the narrative eliciting tool

\begin{tabular}{lrl}
\hline KMO and Bartlett's Test & & \\
\hline Kaiser-Meyer-Olkin measure of sampling adequacy & & \\
& Approx. Chi-Square & \\
Bartlett's test of sphericity & df & 210 \\
& Sig. & 0.000 \\
\hline
\end{tabular}

JMR

Table 4. Total variance explained

\begin{tabular}{|c|c|c|c|c|c|c|c|c|c|}
\hline \multirow{2}{*}{ 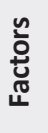 } & \multicolumn{3}{|c|}{ Initial Eigenvalues } & \multicolumn{3}{|c|}{ Extraction Sums of Squared Loadings } & \multicolumn{3}{|c|}{ Rotation Sums of Squared Loadings } \\
\hline & Total & $\begin{array}{c}\% \text { of } \\
\text { variance }\end{array}$ & $\begin{array}{c}\text { Cumulative } \\
\%\end{array}$ & Total & $\begin{array}{l}\% \text { of vari- } \\
\text { ance }\end{array}$ & Cumulative \% & Total & $\begin{array}{c}\% \text { of } \\
\text { variance }\end{array}$ & $\begin{array}{l}\text { Cumula- } \\
\text { tive \% }\end{array}$ \\
\hline 1 & 8.639 & 41.139 & 41.139 & 4.710 & 22.430 & 22.430 & 4.407 & 20.986 & 20.986 \\
\hline 2 & 2.366 & 11.269 & 52.408 & 5.012 & 23.868 & 46.298 & 3.303 & 15.727 & 36.714 \\
\hline 3 & 1.888 & 8.991 & 61.399 & 2.015 & 9.594 & 55.892 & 2.704 & 12.876 & 49.590 \\
\hline 4 & 1.295 & 6.168 & 67.566 & .992 & 4.723 & 60.615 & 2.315 & 11.025 & 60.615 \\
\hline
\end{tabular}

JMR

Table 5. Narrative measures by age

\begin{tabular}{|c|c|c|c|c|c|}
\hline \multirow{2}{*}{$\begin{array}{c}\text { Variables } \\
\text { A. Microstructure }\end{array}$} & \multirow[b]{2}{*}{ Categories } & \multicolumn{3}{|c|}{ Mean \pm SD } & \multirow[b]{2}{*}{$\mathbf{P}$} \\
\hline & & $\begin{array}{l}7 \text {-year-old } \\
\pm n=16\end{array}$ & $\begin{array}{l}\text { 9-year-old } \\
\pm n=16\end{array}$ & $\begin{array}{c}\text { 11-year-old } \\
\pm n=16\end{array}$ & \\
\hline \multirow{4}{*}{ I. Sentence structure } & 1. Compound sentence & $* 2.50 \pm 3.94$ & $3.93 \pm 4.55$ & $6.68 \pm 7.00$ & 0.028 \\
\hline & 2. Complex sentence & $2.50 \pm 1.54$ & $4.37 \pm 1.62$ & $7.25 \pm 1.94$ & 0.000 \\
\hline & 3. Negative sentence & $4.68 \pm 2.52$ & $4.87 \pm 2.87$ & $4.31 \pm 2.65$ & 0.834 \\
\hline & 4. Interrogative sentence & $1.68 \pm 2.12$ & $1.68 \pm 2.67$ & $1.62 \pm 1.58$ & 0.886 \\
\hline \multirow{5}{*}{ II. Reference } & 1. Full noun phrases & $26.25 \pm 10.56$ & $30.87 \pm 9.38$ & $33.31 \pm 10.81$ & 0.154 \\
\hline & 2. Independent pronouns & $4.18 \pm 2.94$ & $5.06 \pm 4.28$ & $3.06 \pm 2.14$ & 0.500 \\
\hline & 3. Dependent pronouns & $13.43 \pm 6.01$ & $15.93 \pm 8.90$ & $14.18 \pm 5.49$ & 0.585 \\
\hline & 4. Complete ellipsis & $20.50 \pm 6.77$ & $20.75 \pm 8.33$ & $22.87 \pm 9.62$ & 0.677 \\
\hline & 5. Inflection of the verb & $46.43 \pm 7.95$ & $49.75 \pm 14.85$ & $54.06 \pm 13.73$ & 0.237 \\
\hline \multirow{5}{*}{ III. Conjunctions } & 1. Associative conjunctions & $3.31 \pm 4.94$ & $6.18 \pm 4.81$ & $8.93 \pm 7.72$ & 0.004 \\
\hline & 2. Additive conjunctions & $7.31 \pm 4.37$ & $8.62 \pm 5.35$ & $7.31 \pm 3.45$ & 0.639 \\
\hline & 3. Adversative conjunctions & $0.62 \pm 1.14$ & $0.81 \pm 1.27$ & $1.06 \pm 1.73$ & 0.690 \\
\hline & 4. Developmental markers & $14.18 \pm 8.01$ & $18.12 \pm 8.92$ & $16.00 \pm 10.35$ & 0.482 \\
\hline & 1. Number of total words & $237.56 \pm 54.42$ & $302.12 \pm 89.91$ & $306.56 \pm 92.73$ & 0.012 \\
\hline \multirow{7}{*}{ IV. Measures of story length } & a. Noun & $51.18 \pm 14.79$ & $67.00 \pm 16.36$ & $70.31 \pm 14.68$ & 0.002 \\
\hline & b. Verb & $58.12 \pm 10.39$ & $63.37 \pm 19.29$ & $67.18 \pm 14.69$ & 0.251 \\
\hline & c. Adjective & $5.12 \pm 6.64$ & $3.93 \pm 3.21$ & $6.31 \pm 5.21$ & 0.139 \\
\hline & d. Adverb & $21.43 \pm 11.53$ & $16.25 \pm 7.63$ & $18.43 \pm 6.95$ & 0.433 \\
\hline & e. Preposition & $13.81 \pm 4.26$ & $18.75 \pm 8.60$ & $21.68 \pm 7.03$ & 0.008 \\
\hline & 2. Number of total sentences & $45.62 \pm 8.79$ & $52.50 \pm 14.50$ & $56.25 \pm 12.90$ & 0.056 \\
\hline & 3. Semantic information & $60.43 \pm 5.15$ & $71.00 \pm 7.12$ & $77.68 \pm 3.78$ & 0.000 \\
\hline \multirow{3}{*}{ B. Macrostructure } & 1. Initiating event & $1.18 \pm 0.40$ & $1.68 \pm 0.47$ & $1.81 \pm 0.40$ & 0.001 \\
\hline & 2. Attempts & $2.00 \pm 0.00 \mathrm{a}$ & $2.00 \pm 0.00 \mathrm{a}$ & $2.00 \pm 0.00 \mathrm{a}$ & ----- \\
\hline & 3. Resolution & $1.62 \pm 0.50$ & $1.87 \pm 0.34$ & $1.93 \pm 0.25$ & 0.060 \\
\hline
\end{tabular}

* The significant differences are shown in bold type.

JMR

a. Test cannot be done because the standard deviations of all groups are 0 . 
structures, references, conjunctions, and measures of story length at the level of microstructure, and initiating event, attempts, and resolution, at the level of macrostructure were obtained (Table 2).

As shown in Table 2, all correlations were statistically significant for compound sentences ( $\mathrm{r}[46]=0.885, \mathrm{P}<0.001)$, complex sentences ( $\mathrm{r}[46]=0.838, \mathrm{P}<0.001)$, negative sentences $(\mathrm{r}[46]=0.457, \mathrm{P}<0.001)$ and interrogative sentences $(\mathrm{r}=0.613, \mathrm{P}<0.001)$. Accordingly, the correlation between the two phases of the test conducting was significant at the level of confidence of $99 \%(\mathrm{P}<0.001)$.

The same analysis was also applied to assess the correlation of references, conjunctions, measures of story length at the microstructure level. Similarly, all correlations were significantly meaningful at the $99 \%$ confidence level $(\mathrm{P}<0.001)$ between the two phases of the tests.

Moreover, at the level of macrostructure, the correlation of three elements of the story grammar was assessed. Two of them, i.e., the initiating event $(\mathrm{r}[46]=0.788, \mathrm{P}<0.001)$ and resolution ( $\mathrm{r}[46]=0.434, \mathrm{P}<0.001$ ) between two phases of the test conducting was significantly meaningful at $99 \%$ confidence level $(\mathrm{P}<0.001)$. Because the subjects' performances were the same in both test and retest phases (i.e., all subjects achieved the maximum score for each phase of the test), it was impossible to calculate the correlation because of the lack of dispersion.

\section{The validity of the narrative eliciting tool}

Concerning the second study question, the validity of the narrative eliciting tool was evaluated using the construct validity method. For this purpose, confirmatory factor analysis was performed using the varimax method. A study of the suitability of the data was also done using the KMO and Bartlett's test (Table 3).

According to Table 3, the KMO and Bartlett's test of sphericity results indicate that confirmatory factor analysis is acceptable. Using the varimax rotation, we achieved four

Table 6. Narrative measures by gender

\begin{tabular}{|c|c|c|c|c|}
\hline \multirow{2}{*}{$\begin{array}{c}\text { Variables } \\
\text { A. Microstructure }\end{array}$} & \multirow{2}{*}{ Categories } & \multicolumn{2}{|c|}{ Mean \pm SD } & \multirow{2}{*}{$\mathbf{P}$} \\
\hline & & Male(n=24) & Female( $n=24)$ & \\
\hline \multirow{5}{*}{ I. Sentence structure } & 1. Compound sentence & $3.75 \pm 6.42$ & $5.00 \pm 4.45$ & 0.061 \\
\hline & 2. Complex sentence & $4.70 \pm 2.56$ & $4.70 \pm 2.67$ & 0.859 \\
\hline & 3. Negative sentence & $4.04 \pm 2.51$ & $5.20 \pm 2.68$ & 0.127 \\
\hline & 4. Interrogative sentence & $1.00 * \pm 1.21$ & $2.33 \pm 2.61$ & 0.033 \\
\hline & 1. Full noun phrases & $27.66 \pm 8.63$ & $32.62 \pm 11.70$ & 0.102 \\
\hline \multirow{5}{*}{ II. Reference } & 2. Independent pronouns & $3.25 \pm 1.93$ & $4.95 \pm 4.09$ & 0.288 \\
\hline & 3. Dependent pronouns & $12.79 \pm 5.92$ & $16.25 \pm 7.47$ & 0.083 \\
\hline & 4. Complete ellipsis & $21.45 \pm 8.98$ & $21.29 \pm 7.56$ & 0.687 \\
\hline & 5. Inflection of the verb & $48.50 \pm 12.71$ & $51.66 \pm 12.71$ & 0.260 \\
\hline & 1. Associative conjunctions & $5.66 \pm 7.23$ & $6.62 \pm 5.30$ & 0.242 \\
\hline \multirow{4}{*}{ III. Conjunctions } & 2. Additive conjunctions & $7.87 \pm 4.68$ & $7.62 \pm 4.22$ & 0.926 \\
\hline & 3. Adversative conjunctions & $0.54 \pm 0.97$ & $1.12 \pm 1.67$ & 0.190 \\
\hline & 4. Developmental markers & $16.54 \pm 11.29$ & $15.66 \pm 6.41$ & 0.743 \\
\hline & 1. Number of total words & $274.54 \pm 87.45$ & $289.62 \pm 84.39$ & 0.458 \\
\hline \multirow{7}{*}{ IV. Measures of story length } & a. Noun & $59.79 \pm 16.23$ & $65.87 \pm 17.89$ & 0.224 \\
\hline & b. Verb & $59.33 \pm 13.98$ & $66.45 \pm 16.14$ & 0.109 \\
\hline & c. Adjective & $2.87 \pm 1.77$ & $7.37 \pm 6.43$ & 0.004 \\
\hline & d. Adverb & $16.58 \pm 7.34$ & $20.83 \pm 10.12$ & 0.112 \\
\hline & e. Preposition & $16.91 \pm 6.86$ & $19.25 \pm 8.02$ & 0.226 \\
\hline & 2. Number of total sentences & $50.58 \pm 13.76$ & $52.33 \pm 12.06$ & 0.642 \\
\hline & 3. Semantic information & $69.12 \pm 10.55$ & $70.29 \pm 7.26$ & 0.658 \\
\hline \multirow{3}{*}{ B. Macrostructure } & 1. Initiating event & $1.58 \pm .503$ & $1.54 \pm 0.50$ & 0.773 \\
\hline & 2. Attempts & $2.00 \pm 0.00 a$ & $2.00 \pm 0.00 a$ & ---- \\
\hline & 3. Resolution & $1.66 \pm .48$ & $1.95 \pm 0.20$ & 0.010 \\
\hline
\end{tabular}

* The significant differences are shown in bold type.

a. Test cannot be done because the standard deviations of all groups are 0 . 
factors. All these factors, i.e., sentence structures, references, conjunctions, and measures of story length, account for nearly $61 \%$ of the total variance (Table 4 ).

\section{The effect of age and gender on narrative features}

To test the third study question, we compared the use of all narrative features between three age groups. Since the sample size was small, at first, we examined the normality assumption to select the appropriate test. If the assumption of normality and variance equality of observations were met in the three age groups, 1-way ANOVA would be used to examine this question. If it was met, but the variance equality of the three groups was violated, the Welch test would be used. And if both normality and variance equality were violated, the non-parametric Kruskal-Wallis test would be used. The results indicated that, almost in all cases, using different narrative features increased by an increase in age. However, this was statistically significant in some cases, as shown in bold type in Table 5 .

To answer the fourth study question, we compared the mean value of using each narrative feature between two genders (boys vs. girls). Since the sample size of the data was small, at first, we examined the normality assumption to select the appropriate test. If the samples were normal in both groups, the independent paired-sample t test would be used. The statistics of this test depend on the variance of the two groups, whether equal or unequal. However, if the distribution of the observations was not normal in both groups or one of the groups, a non-parametric Mann-Whitney test should be used. Regarding the mean values of the two gender groups, the mean use of different narrative features was higher in the girls' narratives. However, this difference was statistically significant only in some categories. The results showed a significant difference between boys and girls in using interrogative sentences and adjectives at the microstructure level and the resolution at the macrostructure level (given in bold type in Table 6).

\section{Discussion}

This study aimed to examine the reliability and validity of a tool for eliciting oral narratives produced by Persianspeaking children based on the picture storybook, "Frog, where are you?" [47]. Also, we intended to study the effect of age and gender factors on the eliciting power of this narrative tool in the Persian language. Along with this purpose, this study aimed to determine and analyze the discursive features which were efficient in assessing a narrative at microstructure and macrostructure levels. Hence, among the various narrative elements, five categories with their most pertinent subsets for assessing Persian narratives were specified at the microstructure level: 1. sentence structure, including compound, complex, negative, and interrogative sentences; 2. references, including full noun phrases, independent pronouns, dependent pronouns, complete ellipsis and inflection of the verb; 3. conjunctions, including associative, additive, adversative, and developmental marker; and 4. measures of story length, including the number of total words (e.g., noun, verb, adjective, etc.), number of total sentences, and semantic information. Besides, at the level of macrostructure, initiating event, attempts, and resolution were determined for narrative assessment.

Although Persian-speaking narrative skills and narrative eliciting tools have not been effectively explored, it has recently received more attention for its clinical and diagnostic implications. Soleymani et al. claimed that "Frog, where are you?" picture storybook [47] did not reliably make Persianspeaking children tell a narration [46]. In this respect, their findings differ from the current research, because we found that Persian-speaking elementary school children produced narrations based on the "Frog, where are you?" story. The results related to the correlation coefficient of measures of story length, specifically, the total number of the sentences, confirmed that this picture storybook could be a reliable tool for eliciting and assessing Persian-speaking children's narratives in the age groups of 7, 9, and 11 years old.

Regarding the reliability and validity of the data under investigation at the level of microstructure (sentence structures, references, conjunctions, and measures of story length) and at the level of macrostructure (initiating event, attempts, and resolution), findings were consistent with the previous findings $[14,16,55]$. In other words, narrative assessment is an efficient tool to provide a wide variety of linguistic information $[36,37]$ about individual speakers. Particularly, the significantly high correlation of the results in test-retest phases concur with the literature that suggests picture storybook, "Frog, where are you?" [47] is a reliable and valid tool for eliciting narratives from Persian-speaking children. This tool can assess their narrative characteristics, in terms of discursive features at microstructure and macrostructure levels.

Although the current data revealed the reliability and validity of this tool for investigating narratives produced by Persian-speaking children, further studies on the current topic are required to validate the findings in the other age groups of typically-developed children, and the ones with language impairment as well.

The other main findings indicated that older children generally used more discursive features. This finding can be considered as an interrelated effect with cognitive and lin- 
guistic development. For example, in the younger children's narratives, simple sentences are dominant. Therefore, using compound or complex sentences is associated with age. This fact can be attributed to associative conjunctions, the number of total words, nouns, prepositions, semantic information, and initiating event use. This finding is in line with the previous studies $[38,39]$, which indicated the developmental acquisition nature of narratives at microstructure and macrostructure levels $[15,27,31]$. Nonetheless, the results revealed that the gender factor could have a minimal influence on the use of different discursive features than age. For instance, girls consistently used the key interrogative sentence of the story (e.g., /qurbaqe, kodzaji?/ "Frog, where are you?") or adjectives (e.g., /sæge Jejtun/ "the naughty dog") to describe the characters. Consequently, even though these results differ from some previous studies [41-43], they are consistent with those proposed the negligible effect of gender in using discursive features [44, 45, 49].

\section{Conclusion}

This research, as a preliminary study, investigated the reliability and validity of a narrative eliciting tool for analyzing Persian data. Test-retest results and confirmatory factor analysis demonstrated that the tool could be useful and informative for analyzing Persian-speaking children's narratives at the microstructure and macrostructure levels. Given the valuable function of narrative skills in the social and academic life, assessing various aspects of the narrative, concerning different effective factors, in typically-developed children and also children with different cognitive and linguistic disorders, can help us find what measures require particular intervention, as a clinical implication or educational planning.

\section{Ethical Considerations}

\section{Compliance with ethical guidelines}

To conduct the eliciting narrative test, we first took formal permission from Mashhad Education and Training Administration. Then, the children's parents and teachers signed the consent form.

\section{Funding}

The authors received no financial support for the research, authorship, and or publication of this article.

\section{Authors contributions}

Conceptualization: Setareh Mojahedi Rezaeian, Abbas Ali Ahangar; Methodology: Setareh Mojahedi Rezaeian, Abbas
Ali Ahangar, Peyman Hashemian; Software, validation, formal analysis: Setareh Mojahedi Rezaeian, Mehrdad Mazaheri; Investigation, resources, data curation, writing the original draft: Setareh Mojahedi Rezaeian; Writing the review and editing: Setareh Mojahedi Rezaeian, Abbas Ali Ahangar.

\section{Conflict of interest}

The authors declared no conflicts of interest.

\section{Acknowledgments}

The authors gratefully acknowledge Mashhad Education and Training Office, District 7, the staffs and teachers at Hojjat ordinary elementary school and especially all the children who participated in the study, and their parents cooperated kindly.

\section{References}

[1] Boudreau DM. Narrative abilities in children with language impairments. In: Paul R, editor. New Directions in Communication Disorders Research: Integrative Approaches. Language Disorders from a Developmental Perspective: Essays in Honor of Robin S. Chapman. New Jersey: Lawrence Erlbaum Associates Publishers; 2007. p. 331-56. https://psycnet.apa.org/record/2006-20176-013

[2] Levinsohn SH. Self-instruction materials on narrative discourse analysis. Dallas, TX: SIL International; 2015. https://www.sil. org/resources/archives/68643

[3] Rumelhart DE. Notes on a schema for stories. In: Bobrow DG, Collins A, editors. Representation and Understanding: Studies in Cognitive Science. New York: Academic Press; 1975. p. 211-36. https:/ / books.google.com/books?id=Pd9OAAAAMAAJ\&dq

[4] Kibrik A. Reference in discourse. Oxford: Oxford University Press; 2011. [DOI:10.1093/acprof:oso/9780199215805.001.0001] [PMID]

[5] Botting N, Faragher B, Simkin Z, Knox E, Conti-Ramsden G, Predicting pathways of specific language impairment: What differentiates good and poor outcome? The Journal of Child Psychology and Psychiatry and Allied Disciplines. 2001; 42(8):101320. [DOI:10.1111/1469-7610.00799] [PMID]

[6] Cleave PL, Girolametto LE, Chen X, Johnson CJ. Narrative abilities in monolingual and dual language learning children with specific language impairment. Journal of Communication Disorders. 2010; 43(6):511-22. [DOI:10.1016/j.jcomdis.2010.05.005] [PMID]

[7] Fey ME, Catts HW, Proctor Williams K, Tomblin JB, Zhang X Oral and written story composition skills of children with language impairment. Journal of Speech, Language, and Hearing Research. 2004; 47(6):1301-18. [DOI:10.1044/1092-4388(2004/098)]

[8] Gorman BK, Bingham GE, Fiestas CE, Terry NP. Assessing the narrative abilities of Spanish-speaking preschool children: A Spanish adaptation of the narrative assessment protocol. Early Childhood Research Quarterly. 2016; 36:307-17. [DOI:10.1016/j. ecresq.2015.12.025] 
[9] Jones C, Toscano E, Botting N, Marshall CR, Atkinson JR, Denmark T, et al. Narrative skills in deaf children who use spoken English: Dissociations between macro and microstructural devices. Research in Developmental Disabilities. 2016; 59:268-82. [DOI:10.1016/j.ridd.2016.09.010] [PMID]

[10] Norbury CF, Bishop DV. Narrative skills of children with communication impairments. International Journal of Language \& Communication Disorders. 2003; 38(3):287-313. [DO I:10.1080/136820310000108133] [PMID]

[11] Paris AH, Paris SG. Assessing narrative comprehension in young children. Reading Research Quarterly. 2003; 38(1):3676. [DOI:10.1598/RRQ.38.1.3]

[12] Reese E, Sparks A, Suggate S. Assessing children's narratives. In: Hoff E, editor. Research Methods in Child Language: A Practical Guide. Hoboken, NJ: Wiley-Blackwell; 2012. p. 133-48. [DOI:10.1002/9781444344035.ch9]

[13] Reilly J, Losh M, Bellugi U, Wulfeck B. “Frog, where are you?" Narratives in children with specific language impairment, early focal brain injury, and Williams syndrome. Brain and Language. 2004; 88(2):229-47. [DOI:10.1016/S0093934X(03)00101-9]

[14] Justice LM, Bowles RP, Kaderavek JN, Ukrainetz TA, Eisenberg SL, Gillam RB. The index of narrative microstructure: A clinical tool for analyzing school-age children's narrative performances. American Journal of Speech-Language Pathology. 2006; 15(2):177-91. [DOI:10.1044/1058-0360(2006/017)]

[15] Hickmann M. Children's discourse: Person, space and time across languages. Cambridge: Cambridge University Press; 2004 https:// books.google.com/books?id=kowdw72y4HsC\&dq

[16] Justice LM, Bowles R, Pence K, Gosse C. A scalable tool for assessing children's language abilities within a narrative context: The NAP (Narrative Assessment Protocol). Early Childhood Research Quarterly. 2010; 25(2):218-34. [DOI:10.1016/j. ecresq.2009.11.002]

[17] Liles BZ. Production and comprehension of narrative discourse in normal and language disordered children. Journal of Communication Disorders. 1985; 18(6):409-27. [DOI:10.1016/00219924(85)90030-9]

[18] Paul R, Norbury C. Language disorders from infancy through adolescence: Listening, speaking, reading, writing, and communicating. $4^{\text {th }}$ ed. St. Louis: Mosby; 2012. https://books.google. com/books?id=maGQtryS8xcC\&dq

[19] Pinto G, Tarchi C, Bigozzi L. Development in narrative competences from oral to written stories in five-to seven-year-old children. Early Childhood Research Quarterly. 2016; 36:1-10. [DOI:10.1016/j.ecresq.2015.12.001]

[20] Carroll DW. Psychology of language. Belmont, CA Thomson Wadsworth; 2008. https://books.google.com/ books?id=qaatrAHKPRAC\&dq

[21] Berman RA. Narrative competence and storytelling performance: How children tell stories in different contexts. Journal of Narrative and Life History. 1995; 5(4):285-313. [DOI:10.1075/ jnlh.5.4.01nar]

[22] Trabasso T, van den Broek P. Causal thinking and the representation of narrative events. Journal of Memory and Language. 1985; 24(5):612-30. [DOI:10.1016/0749-596X(85)90049-X]
[23] Heilmann J, Miller JF, Nockerts A, Dunaway C. Properties of the narrative scoring scheme using narrative retells in young school-age children. American Journal of SpeechLanguage Pathology. 2010; 19(2):154-66. [DOI:10.1044/10580360(2009/08-0024)]

[24] Stein NL, Glenn CG. An analysis of story comprehension in elementary school children. In: Freedle RO, editor. New Directions in Discourse Processing. Norwood, NJ: Ablex Publishing Corporation; 1979. p. 53-120. https://books.google. com/books?id=mowoAAAAYAAJ\&dq

[25] Stein NL. What's in a story: Interpreting the interpretations of story grammars. Discourse Processes. 1982; 5(3-4):319-35. [DOI:10.1080/01638538209544548]

[26] Trabasso T, Stein NL. Using goal-plan knowledge to merge the past with the present and the future in narrating events on line. In: Haith MM, Benson JB, Roberts Jr RJ, Pennington BF, editors. The Development of Future-Oriented Processes. Chicago, IL: University of Chicago Press; 1994. p. 323-49. https:/ / books. google.com/books?id=tWr-RDU9hWgC\&dq

[27] Berman RA, Slobin DI. Relating events in narrative: A crosslinguistic developmental study. Mahwah, NJ: Lawrence Erlbaum Associates; 1994. https:/ / books.google.com/ books?id=lWJhuwEACAAJ\&dq

[28] Liles BZ, Duffy RJ, Merritt DD, Purcell SL. Measurement of narrative discourse ability in children with language disorders. Journal of Speech, Language, and Hearing Research. 1995; 38(2):415-25. [DOI:10.1044/jshr.3802.415] [PMID]

[29] Faulkner D, Coates E. Exploring children's creative narratives: Some theoretical, methodological and applied perspectives. In: Faulkner D, Coates E, editors. Exploring Children's Creative Narratives. Abingdon: Routledge; 2011. p. 1-10. https://books.google.com/books?id=khDXpyGxMWkC\&dq

[30] Westby CE. Assessing and remediating text comprehension problems. In: Catts HW, Kamhi AG, editors. Language and Reading Disabilities. London/Boston, MA: Pearson/Allyn and Bacon; 2005. p. 157-232. https://books.google.com/ books?id=XwxKAAAAYAAJ\&dq

[31] Trabasso T, Nickels M. The development of goal plans of action in the narration of a picture story. Discourse Processes. 1992; 15(3):249-75. [DOI:10.1080/01638539209544812]

[32] Dabir-Moghaddam M. [Theoretical linguistics: Emergence and development of the generative grammar (Persian)]. $4^{\text {th }}$ ed. Tehran: SAMT; 2010. http://opac.nlai.ir/opac-prod/bibliographic/1791627

[33] Hughes DL, McGillivray L, Schmidek M. Guide to narrative language: Procedures for assessment. Eau Claire, WI Thinking Publications; 1997. https://books.google.com/ books?id=QNINAAAACAAJ\&dq

[34] Heilmann J, DeBrock L, Chris Riley-Tillman T. Stability of measures from children's interviews: The effects of time, sample length, and topic. American Journal of Speech-Language Pathology. 2013; 22(3):463-75. [DOI:10.1044/10580360(2012/11-0035)]

[35] Kaplan RM, Saccuzzo DP. Psychological testing: Principles, applications, and issues. Belmont, CA: Wadsworth Cengage Learning; 2013. https://books.google.com/ books?id=Bn8yZXdPM1wC\&vq 
[36] Pankratz ME, Plante E, Vance R, Insalaco DM. The diagnostic and predictive validity of the renfrew bus story. Language, Speech, and Hearing Services in Schools. 2007; 38(4):390-9. [DOI:10.1044/0161-1461(2007/040)]

[37] Patten ML, Newhart M. Understanding research methods: An overview of the essentials. New York: Routledge; 2018. https:/ / books.google.com/books?id=YAoqDwAAQBAJ\&dq

[38] Price JR, Roberts JE, Jackson SC. Structural development of the fictional narratives of African American preschoolers. Language, Speech, and Hearing Services in Schools. 2006; 37(3):178-90. [DOI:10.1044/0161-1461(2006/020)]

[39] Mäkinen L, Loukusa S, Nieminen L, Leinonen E, Kunnari $\mathrm{S}$. The development of narrative productivity, syntactic complexity, referential cohesion and event content in four-to eightyear-old Finnish children. First Language. 2014; 34(1):24-42 [DOI:10.1177/0142723713511000]

[40] Westerveld MF, Moran CA. Spoken expository discourse of children and adolescents: Retelling versus generation. Clinical Linguistics \& Phonetics. 2013; 27(9):720-34. [DOI:10.3109/02699 206.2013.802016] [PMID]

[41] Halpern DF. Sex differences in cognitive abilities. Psychology Press; 2013. [DOI:10.4324/9780203816530]

[42] Hyde JS, Linn MC. Gender differences in verbal ability: A meta-analysis. Psychological Bulletin. 1988; 104(1):53-69. [DOI:10.1037/0033-2909.104.1.53]

[43] Pezzuti L, Orsini A. Are there sex differences in the Wechsler Intelligence Scale for children-forth edition? Learning and Individual Differences. 2016; 45:307-12. [DOI:10.1016/j.lindif.2015.12.024]

[44] Lynch JS, van den Broek P, Kremer KE, Kendeou P, White MJ Lorch EP. The development of narrative comprehension and its relation to other early reading skills. Reading Psychology. 2008; 29(4):327-65. [DOI:10.1080/02702710802165416]

[45] Toivainen T, Papageorgiou KA, Tosto MG, Kovas Y. Sex differences in non-verbal and verbal abilities in childhood and adolescence. Intelligence. 2017; 64:81-8. [DOI:10.1016/j.intell.2017.07.007]

[46] Soleymani Z, Nematzadeh Sh, Gholami Tehrani L, Rahgozar M, Schneider P. Language sample analysis: Development of a valid language assessment tool and determining the reliability of outcome measures for Farsi-speaking children. European Journal of Developmental Psychology. 2016; 13(2):275-91. [DOI:10.10 80/17405629.2016.1152175]

[47] Mayer M. Frog, where are you? New York: Dial Press; 1969. https:// books.google.com/books?id=8hrhAAAAMAAJ\&dq

[48] Schneider P, Hayward D, Dubé RV. Storytelling from pictures using the Edmonton narrative norms instrument. Journal of Speech-Language Pathology and Audiology. 2006; 30(4):22438. http://www.rehabresearch.ualberta.ca/enni/sites/default/ files/schneider_article.pdf

[49] Qasemi M, Nakhshab M, Alineghad B, Shafiei M, Tazhibi M [Description of particular language structures in normal 4-yearolds' narrations and their sex-related differences according to Narrative Assessment Protocol (NAP) (Persian)]. Research in Rehabilitation Sciences. 2012; 8(4):704-18. http://jrrs.mui.ac.ir/ index.php/jrrs/article/view/427
[50] Owens RE. Language development: An introduction. London: Pearson; 2012. https://books.google.com/ books?id=JmKVuAAACAAJ\&dq

[51] Serratrice L. Referential cohesion in the narratives of bilingual English-Italian children and monolingual peers. Journal of Pragmatics. 2007; 39(6):1058-87. [DOI:10.1016/j.pragma.2006.10.001]

[52] Botting N. Narrative as a tool for the assessment of linguistic and pragmatic impairments. Child Language Teaching and Therapy. 2002; 18(1):1-21. [DOI:10.1191/0265659002ct224oa]

[53] Duinmeijer I, Jong JD, Scheper A. Narrative abilities, memory and attention in children with a specific language impairment. International Journal of Language and Communication Disorders. 2012; 47(5):542-55. [DOI:10.1111/j.1460-6984.2012.00164.x [PMID]

[54] Kang JY. On the ability to tell good stories in another language: Analysis of Korean EFL learners' oral "Frog story" narratives. Narrative Inquiry. 2003; 13(1):127-49. [DOI:10.1075/ ni.13.1.05kan]

[55] McCabe A, Rollins PR. Assessment of preschool narrative skills. American Journal of Speech-Language Pathology. 1994; 3(1):45-56. [DOI:10.1044/1058-0360.0301.45] 


\section{Appendix}

Appendix A. Semantic scoring (Norbury \& Bishop, 2003)

\begin{tabular}{|c|c|}
\hline No. & Semantic Information \\
\hline 1 & Boy had pet frog and dog \\
\hline 2 & Frog in jar \\
\hline 3 & Frog got out/escaped/etc. \\
\hline 4 & In the night/while boy asleep \\
\hline 5 & Next day/in morning/when boy woke \\
\hline 6 & Boy finds frog has gone \\
\hline 7 & Look for frog in boot \\
\hline 8 & Look for frog in jar \\
\hline 9 & Look everywhere \\
\hline 10 & Dog head stuck in jar \\
\hline 11 & Call frog/say/'frog where are you' \\
\hline 12 & Call/look out of window \\
\hline 13 & Dog falls out of window \\
\hline 14 & Jar broken \\
\hline 15 & Boy goes out of house/window \\
\hline 16 & Boy picks up/cuddles dog \\
\hline 17 & Dog licks boy \\
\hline 18 & Boy angry/says dog is naughty \\
\hline 19 & Boy (+dog) calling/looking for frog \\
\hline 20 & Boy and dog go into the woods/forest \\
\hline 21 & Boy looks in/shouts in hole \\
\hline 22 & Creature comes out of hole \\
\hline 23 & Creature bites boy's nose \\
\hline 24 & Dog jumps at tree \\
\hline 25 & Dog barks at bees \\
\hline 26 & Bees come out \\
\hline 27 & Bee swarm (hive) falls/knocked down \\
\hline 28 & Boy looks in hole in tree \\
\hline 29 & Owl comes out of tree \\
\hline 30 & 30. Bees chase dog \\
\hline 31 & Boy falls down \\
\hline 32 & Owl frightens boy \\
\hline 33 & Boy climbs/looks over rock \\
\hline 34 & Boy calls for frog \\
\hline 35 & Boy holds on to antlers \\
\hline 36 & Boy doesn't realize it is a deer \\
\hline 37 & Deer picks up boy \\
\hline 38 & Deer carries/runs with boy \\
\hline 39 & Dog runs after \\
\hline 40 & Deer stops suddenly \\
\hline 41 & Deer ducks/tosses/throws boy \\
\hline 42 & Boy and dog go over cliff \\
\hline 43 & Dog on boy's head \\
\hline 44 & Falls into water \\
\hline 45 & Boy hears frog sound \\
\hline 46 & Boy says shh/tells dog to be quiet \\
\hline 47 & Boy+dog look over/climb over log \\
\hline 48 & Find his/the frog \\
\hline 49 & Frog family (mum dad+babies) \\
\hline 50 & Take home baby frog \\
\hline 51 & Say goodbye to frogs \\
\hline
\end{tabular}


Appendix B. Descriptions and Persian examples of the categories

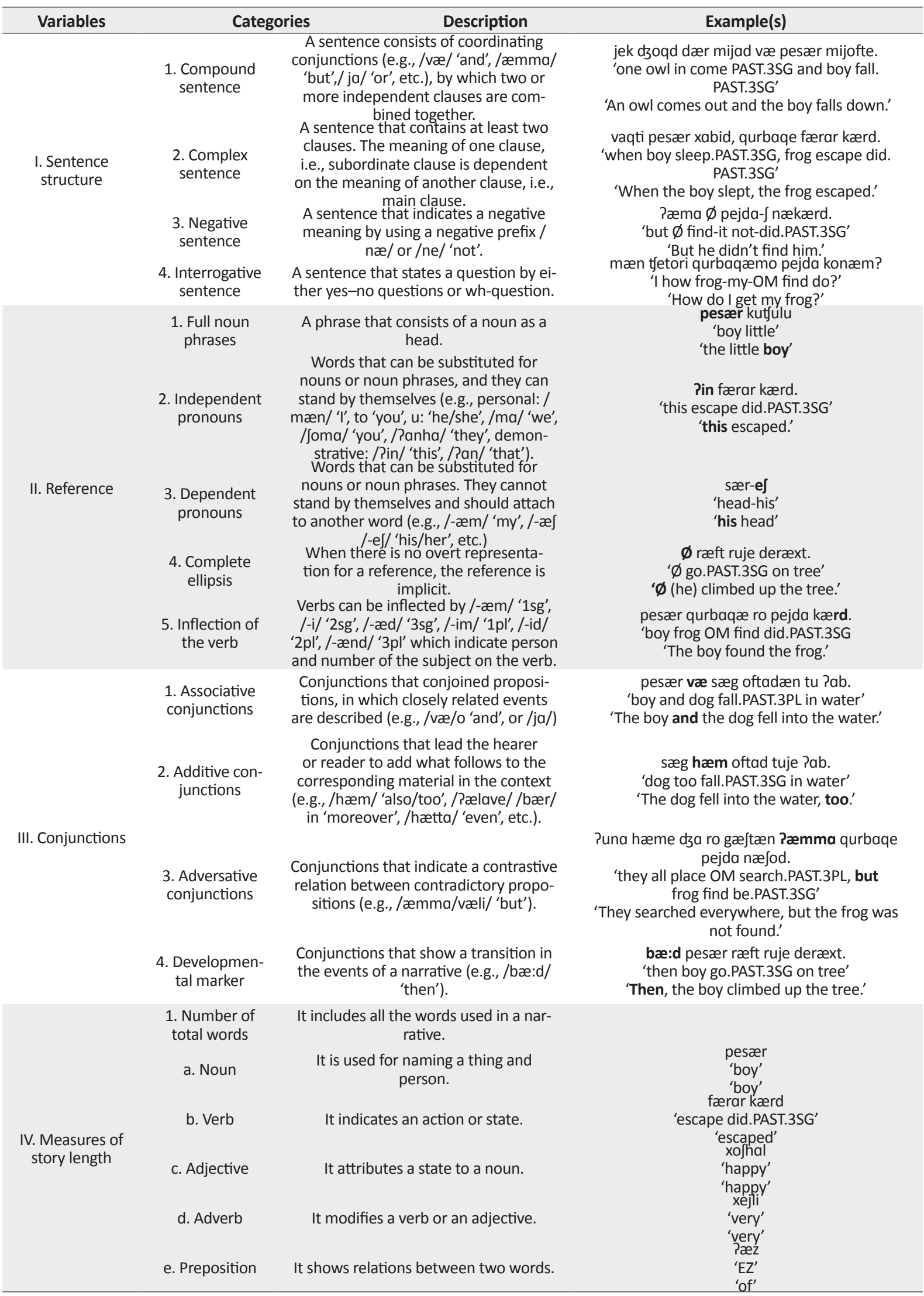




\begin{tabular}{ccc}
\hline Variables & Categories & Description \\
\hline $\begin{array}{c}\text { IV. Measures of } \\
\text { story length }\end{array}$ & $\begin{array}{c}\text { Compound sentences are considered } \\
\text { 2. Number of } \\
\text { total sentences } \\
\text { es as ontences and complex sentenc- } \\
\text { and also independent sentences, } \\
\text { such as negative, and interrogative } \\
\text { sentences comprise NTS. }\end{array}$ \\
& $\begin{array}{c}\text { 3. Semantic } \\
\text { Information }\end{array}$ & $\begin{array}{c}\text { Information the child narrated about } \\
\text { the story (Appendix A) }\end{array}$ \\
\hline
\end{tabular}

Appendix C. List of Abbreviations

\begin{tabular}{ccc}
\hline Abbreviations & Equivalent \\
\hline 3 & $3^{\text {rd }}$ person \\
EZ & ezafe \\
OM & object marker \\
PAST & past tense \\
PL & plural \\
SG & singular \\
\hline
\end{tabular}

